\title{
The Real Aims that Shape the Teaching of Practical Physics in Sub-Saharan Africa
}

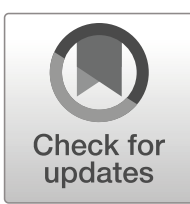

\section{Femi E. Babalola ${ }^{1}$ D $\cdot$ Robert J. Lambourne ${ }^{1} \cdot$ Stephen J. Swithenby ${ }^{1}$}

Received: 3 April 2018 / Accepted: 21 February 2019 / Published online: 15 March 2019

(C) The Author(s) 2019

\begin{abstract}
Practical work is widely seen as an important element of the science curriculum. However, there is a long-standing debate about the educational aims of practical work and about why it is important. Aims suggested include the contributions that practical work can make to understanding, to the acquisition of professional and personal skills, and to motivation. However, several authors have argued that the actual contributions made are minimal and there is ongoing pressure to justify the continuing inclusion of practical work in a period when greater cost efficiency is required from all those involved in education. Such pressures are extreme in countries that face resource challenges. This study examines current views on the aims of practical physics teaching in sub-Saharan Africa. Data were gathered from staff and students in four countries across the region through surveys and interviews. A context was provided by observation of practice and inspection of background documents. The overt educational aims of the staff are consistent with previous analyses though there is a heightened priority given to the improvement of content knowledge and understanding. However, there are additional drivers of behaviour that, to a large extent, define the observed practice. These 'pragmatic aims' concern mainly the practicalities of running schools with limited material and staff resources but also arise from cultural expectations and societal needs. Although the formal data is derived from the secondary sector, it is of relevance to all educational levels.
\end{abstract}

Keywords Motivation · Practical physics · Skills acquisition · Teaching and learning

Femi E. Babalola

ebabalolafemi@yahoo.com

Robert J. Lambourne

robert.lambourne@open.ac.uk

Stephen J. Swithenby

stephen.swithenby@gmail.com

1 School of Physical Sciences, The Open University, Milton Keynes MK7 6AA, UK 


\section{Introduction}

Science is a complex technical and social activity. For this study, the neutral understanding of the aim of science provided by Millar (2010) is adequate. Millar says that the aim of science is to increase our understanding of the natural world, what it is made of, and how it works. Millar asserts further that science teaching involves showing learners certain things (objects, processes, phenomena), or putting them into situations where they can see such things for themselves. The need for exposure follows naturally from science's focus on the physical world.

Lunetta, Hofstein, and Clough (2007, p. 394) have defined practical work as 'learning experiences in which students interact with materials or with secondary sources of data to observe and understand the natural world'. This broad understanding is adopted in this paper.

In countries with a long tradition of laboratory-based science teaching at school level, practical work is seen by many teachers as an essential aspect of their everyday practice. It is often claimed that practical work leads to better learning in that we are more likely to understand and remember things that we have done rather than things we have merely been told. It is also considered by many teachers, and by others with an interest in science education (House of Lords, 2006; Science Community Representing Education [SCORE], 2008), to be the key to catching and holding learners' interest in science and encouraging them to pursue the subject further. Millar's assertion about the need to include practical work in the science curriculum is supported by many educational researchers.

The literature on the aims of practical science extends over many decades. An influential early study by Kerr (1963) investigated the reasons offered within schools for practical work in science. Ten suggested reasons were ranked by teachers. In physics, the highest rank was given to improving investigative skills. Meeting the needs of practical examinations came last.

Kerr's empirical study work was extended by several other authors (Beatty \& Woolnough, 1982; Thompson, 1975). Shulman and Tamir (1973) suggested that the possible aims fall into the following categories (edited for brevity):

1. Acquisition of skills

2. Development of conceptual understanding

3. Development of cognitive abilities

4. Exposure to the nature of science and the scientific method

5. Motivation and promotion of positive attitudes to science and the learning of science

Since 1973, several alternative lists have been devised, each informed by beliefs, theories and practice. For example, in 2004, Parkinson identified 12 distinct aims. These cover similar ground to Shulman and Tamir (1973) but with significant elaboration, notably in skills development.

Many authors (Hodson, 1990; Kerr, 1963; Shulman \& Tamir, 1973) have expressed scepticism that the discussed aims were being met. The difficulties in delivery relate to the ambitious scope of the aims for an activity with limited curriculum time and material resources, the continuing debate about which aims have priority, and disagreement about how to teach practical science. 
There are divergent views on the relative importance of the potential aims of practical work. For example, National Council of Educational Research and Training (NCERT, 2006) proposes that the pedagogy should focus on skills, cognition and exposure to the nature of science, thereby omitting motivational aspirations. Other authors have emphasised that practical work creates motivation and interest for learning physics and that tacit knowledge of scientific phenomena can be gained (Collins, 2011; Lazarowitz \& Tamir, 1994). Millar (1998) has argued that practical work should be viewed as an important means of allowing the physics learners to reconcile and link the physical world with its scientific description. This, it is believed, supports learner engagement.

However, it is still common for practical work to be designed as a ritual activity that yields 'the correct result' for all students (Kang \& Wallace, 2005; Kirschner, 1992; Ünal \& Özdemir, 2013). This may help to consolidate concepts but is unlikely to address other aims.

In many countries in the 1970 s and 1980 s, the aspiration to expose students to 'the nature of science' together with a belief in constructivist approaches promoted a shift from closed recipe-based practical work to more open-ended inquiry and discovery (Baird, 1990; Driver \& Oldham, 1986; Tobin, 1990). However, many teachers have found it difficult to reconcile such approaches with cognitive and conceptually linked aims (Hofstein \& Lunetta, 2003). Many teachers have failed to link hands-on activities with minds-on attitudes. As Mayer (2004) has pointed out, an effective practical pedagogy requires linkage between student discovery and teacher guidance.

The lack of agreement about the role of practical work affects teachers, many of whom lack the equipment, time and knowledge to deliver a practical curriculum that reconciles the aims in Shulman and Tamir's list (Bentley \& Watts, 1991; Bing \& Hao, 2018).

The educational attitudes and beliefs of teachers are crucial in effective curriculum delivery and many authors have carried out empirical studies on teacher attitudes with the hope that such data will inform teacher guidance and training (e.g. Abrahams \& Sağlam, 2010; Beatty \& Woolnough, 1982; SCORE, 2008; Watson, 2000). These studies demonstrate that teachers are consistent in believing that practical work develops understanding, skills, interest and motivation, but the balance between these has evolved in response to political imperatives and scientific practice. These remarks are developed below.

In 1990, Hodson reported that the views of teachers were consistent with five possible aims and justifications of practical work. These were as follows:

1. To motivate by stimulating interest and enjoyment

2. To teach laboratory skills

3. To enhance the learning of scientific knowledge

4. To give insight into the scientific method and develop expertise in using it

5. To develop certain 'scientific attitudes', such as open-mindedness, objectivity and willingness to suspend judgement

Although expressed differently, these aims are very similar to those of Shulman and Tamir (1973). In a further exploration of practical work, Hodson (1998) points out that the teachers often see practical work as a means of obtaining factual information and 
data from which conclusions are later drawn. However, he argues that this kind of teaching approach does not help students to construct their personal understanding of scientific knowledge in a meaningful way as it fails to engage them in the thinking that precedes an experimental investigation.

A 2008 is report commissioned by SCORE, a partnership of seven scientific bodies including the UK Institute of Physics. SCORE set out the views of teachers on the roles of practical work (SCORE, 2008). One thousand and one hundred secondary teachers ( $24 \%$ physicists) were asked to identify the three most important of nine possible aims. It can be seen that teachers support multiple aims (Fig. 1). Skills are regarded as important but so too are the encouragement of pupils, conceptual support and the development of professional attitudes and capabilities.

The main though not exclusive emphasis in the preceding paragraphs is on studies from and about the UK. This is intentional as the UK tradition of practical work is well established and UK approaches have influenced science teaching in much of subSaharan Africa. Woodley (2009) found that teachers in England adopt a hands-on approach to teaching and their students spend more time on practical work than their international counterparts. Unfortunately, the most exhaustive study of relevant classroom practice does not provide data for the allocation of lesson time for practical work in the region (Sturman et al., 2008).

Two studies conducted in the African context are relevant (Fessehatsion, 2003; Ghebremariam, 2000). Both studies were conducted in Eritrea with secondary school teachers. In the Ghebremariam (2000) study, the physics teachers from five selected secondary schools rated the aims of practical work in order of importance as follows:

1. To verify facts and principles already taught or to determine cause and effect

2. To make physical phenomenon more real through actual experience

3. To encourage accurate observation and careful recording

4. To arouse and maintain interest in the subject

5. To promote the understanding of scientific methods or techniques

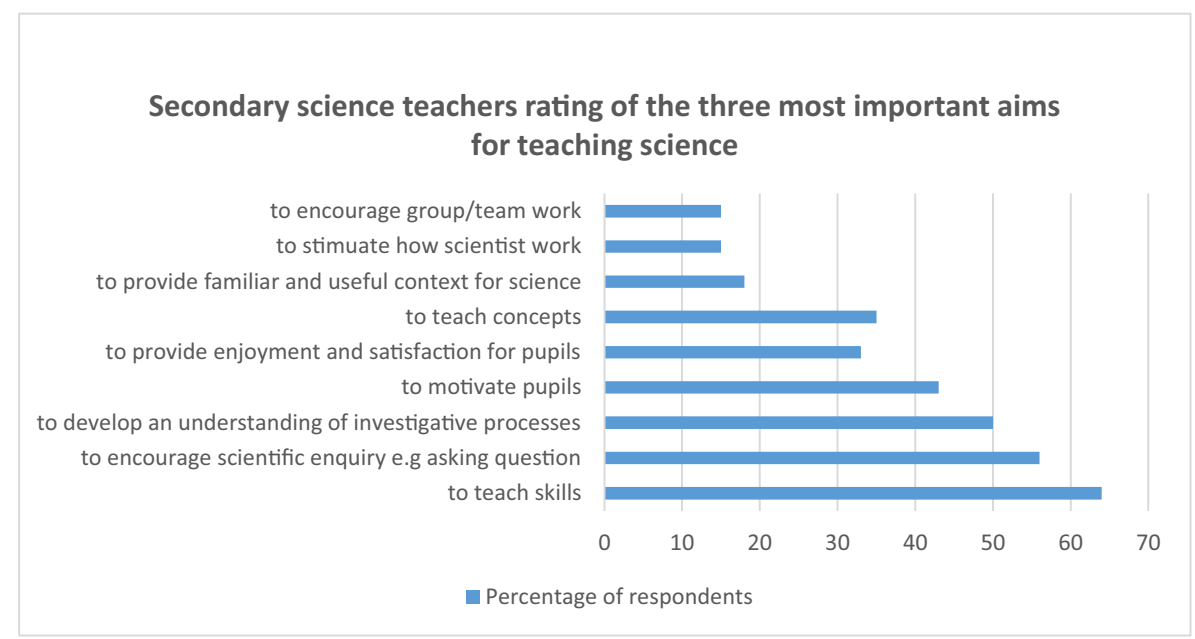

Fig. 1 The perceived importance of the aims of practical science teaching (SCORE, 2008) 
In Fessehatsion's (2003) study, chemistry teachers generated a similar list of important aims. Most aims listed in the studies of Ghebremariam (2000) and Fessehatsion (2003) look very similar to the aims of practical science discussed above but with an enhanced emphasis on the acquisition of content knowledge and little interest in promoting inquiry or exploring the process by which scientific knowledge is expanded. However, it should be acknowledged that any discussion of the aims of practical science is a fraught process. The nuance of words and phrases may not be shared by the deviser of a list and the respondent, or even by two different respondents. Such issues may be magnified when the social and linguistic contexts differ markedly, e.g. between the UK and sub-Saharan Africa (SSA).

The literature suggest that there is a continuing lack of clarity about the aims of practical science teaching (SCORE, 2008) and significant doubt about the effectiveness of much of the practical work carried out. Why? What are the barriers to the development of successful pedagogies?

The SCORE report provides a valuable list of barriers drawn from teachers, technicians and other educational stakeholders (SCORE, 2008). Although based on practical science in general, it may be expected to include many of the issues relevant to physics practical work. The list can be gathered into six areas where difficulties are encountered: the design of the curriculum, material resources, assessment requirements, staff expertise, time pressures and classroom management. It is not difficult to see how such issues can undermine effective delivery of a nuanced area of the curriculum with ambiguous, challenging and challenged aims. In its evidence to a UK Parliamentary Committee, the UK Institute of Physics listed barriers to effective practical work in physics (House of Lords, 2006). These cover similar ground to the SCORE report though they omit curriculum concerns and time pressures. Said et al. arrive at similar conclusions from a study of secondary schools in Qatar but also include inadequate technical support as well as test and assessment requirements that do not prioritise practical work (Said, Friesen \& Al-Azzah, 2014).

At this point, it is relevant to comment briefly on the social and educational background of SSA. There is a rapidly increasing population across the region, a result of the high birth rate. The majority of the SSA population are rural dwellers and there are large differences in access to social and educational amenities between rural and urban areas. Most of the SSA countries have rapidly growing economies but with limited science-related employment except in South Africa. Despite economic growth, government education budgets have not met the $26 \%$ UNESCO target. There is a high rate of unemployment across SSA.

Over the last 20 years, there have been dramatic increases in enrolment at all levels of education, resulting in large class sizes at all educational levels. There is heavy drop out among students, including at the primary level in some countries. Upper secondary and tertiary enrolments lag far behind economically developed countries and there are significant gender disparities in some countries. Physics is part of the teaching curriculum in most secondary schools with governments publishing specific objectives but with limited allocated resources. In several countries, the qualification assessment processes ignore practical work completely. In others, lack of confidence in the ability to run meaningful practical examinations have led to the use of stereotyped predictable experiments or 'alternatives to practical' where students are provided with pre-prepared data to analyse. 
There have been sporadic interventions in SSA designed to improve the teaching of practical physics. These have met with very limited success. This study is aimed at a better understanding of the aims of those involved in teaching and learning of practical physics in SSA. With such understanding, it may be possible to design interventions that are more likely to be successful. There are several groups of stakeholders who influence this system, including teachers, head teachers, educationalists, examiners, and government officials. Students too are relevant as their aspirations and curriculum expectations will affect the choice of teaching approaches.

The specific research questions that are addressed are as follows:

1. What are the educational aims of practical physics teaching in SSA?

2. How do these aims compare with the equivalent aims in economically developed countries?

3. Do the barriers to effective delivery in SSA introduce pragmatic aims that affect the educational aspirations?

\section{Research Methodology and Protocols}

Overview. The data in this study were generated as part of a wider investigation of practical physics education in secondary schools in SSA. The scope included educational aims, present practice, critical factors affecting the quality of provision and mechanisms for quality enhancement. Although all the data can inform an analysis of aims, this report will focus on the data generated regarding the declared aims and the factors that might subvert those aims.

Ethical approval for the research was sought and obtained from the Human Research Ethics Committee of the UK Open University and from the Ministry of Education in each country. In addition, written informed consent was sought from the head teachers of each school and the science/physics teachers who were to be participants in the study. All participants were reassured that there was no personal risk associated with participation, and that they would be free to withdraw from the study at any time without penalty. Their views would be anonymised.

A predominantly qualitative research approach was used. This allowed us to explore the understandings of people from their own view point and to help to create concrete, vivid and meaningful descriptions of incidents and events (Bogdan \& Biklen, 2007). In addition, limited quantitative surveys of students and teachers were used to enable simple comparisons between countries and to triangulate the qualitative data.

Selection of Participants. A significant issue in pursuing this study was the choice of countries and schools to visit and participants to interview. The countries chosen were Ghana GH, South Africa SA, Nigeria NIG and Tanzania TAN. They span SSA and include countries with different levels of economic development.

There were existing contacts in these countries who could facilitate the study. Eighteen secondary schools were visited (Ghana, 3; South Africa, 6; Nigeria, 5; and Tanzania, 4). For reasons of arranging access, the sample of schools was not representative of secondary schools in SSA in that rural schools were under-represented and there was over representation of high achieving schools. However, the range of schools 
allowed the gathering of views from a broad range of educational environments (Table 1).

The main method of data collection was through interviews. A purposive but opportunistic sampling technique was used in selecting 146 stakeholders for interview (Table 2). The aim was to identify people who would provide insight from informed but differing perspectives.

The participants included teaching staff (55) and students (80), as well as physics curriculum officers (4), physics lecturers from teacher-training colleges and universities (12), examiners (2), senior technicians (2), and policy makers and officials from the ministries of education (5) and others (5). The students who were interviewed were rapporteurs from students focus groups organised within the schools. Each focus group was asked to discuss the interview questions and nominate a rapporteur. This procedure was adopted to broaden the range of input to include students who might be too shy or lack the fluency in English to take part in an interview. Rapporteurs were asked to voice the collective views of their groups.

Interview Protocols. Interviews were conducted face to face with participants who had indicated their willingness to participant. There were two interview scripts-for students and for all other stakeholders. For students, the questions were designed to elicit their attitudes and experience of practice and were colloquial in their language, i.e.:

1. What do you do in practical physics classes?

2. What sort of things are you are trying to learn?

3. Do you like studying practical physics?

4. How well are you and your class mates doing?

5. What is the best physics practical session you have had?

6. What would your ideal practical physics session look like?

For the other stakeholders, the questions were more clearly linked to the overall study aims, i.e.:

1. What is the school practical physics curriculum designed to achieve?

2. How successful are the students in learning about practical physics?

3. What influences success in teaching practical physics?

4. How could practical physics teaching be improved?

In each case, follow-up questions were used to clarify opinions expressed or provide elaboration of significant observations. Although these scripts were designed for the broader study, it should be noted that views relevant to this paper were expressed in answers to several of the seed questions. Interviews lasted typically for about $30 \mathrm{~min}$.

The semi-structured interview protocols were developed through informal discussion and simulated interviews with research colleagues after which they were pilot tested in Nigeria to assess whether (i) the questions were understood and provoked fluent responses, (ii) the interviewees provided data that were relevant to the research questions, and (iii) the responses indicated the need for any additional area of questioning. Only minor wording changes were required. The flexibility of the 
Table 1 Key characteristics of the schools visited with student survey numbers

\begin{tabular}{|c|c|c|c|c|c|c|c|}
\hline \multirow[b]{3}{*}{ School type } & \multicolumn{7}{|c|}{ School Location } \\
\hline & \multicolumn{2}{|c|}{ Urban $(44 \%)$} & \multicolumn{2}{|c|}{ Suburban (37\%) } & \multicolumn{2}{|c|}{ Rural (19\%) } & \multirow[b]{2}{*}{ Total } \\
\hline & Male & Female & Male & Female & Male & Female & \\
\hline Coeducational & 43 & 62 & 85 & 100 & 49 & 53 & $392(71 \%)$ \\
\hline Boys only & 31 & 0 & 18 & 0 & 0 & 0 & $49(9 \%)$ \\
\hline Girls only & 0 & 109 & 0 & 0 & 0 & 0 & $109(20 \%)$ \\
\hline Total & 74 & 171 & 103 & 100 & 49 & 53 & 550 \\
\hline Total & 245 & & 203 & & 102 & & 550 \\
\hline
\end{tabular}

instrument allowed probing of views and opinions but also permitted respondents to develop and expand their responses freely.

The audio recordings were transcribed verbatim. Nvivo Pro 11 version for Windows (QSR International Pty Ltd) was used to organise the data by coding the transcripts into nodes which provided easy retrieval of the themes that emerged. The approach was essentially ethnographic. Candidate themes were independently identified by two researchers who attempted to represent areas of comment while being mindful of the previous structuring of theoretical analyses. Typically, each node contained a range of opinions. Following this preliminary analysis, the themes and their definitions were finalised. Where quotes are used in this paper, they were chosen because they were representative of statements made by several respondents.

Survey Protocols. Two short surveys were carried out on 44 of the school teaching staff interviewed and on 550 students (41\% female, median age 17 years). The teaching staff survey had an age distribution as follows: 9 below 30 years, 18 (30 to 39 years), 10 (40 to 49 years) and 7 (50 to 59 years). Twenty-four of the teachers had qualifications at first degree level or above. The other 20 were qualified at diploma level—many of these had limited experience of carrying out practical work as students. All of the teachers were science trained- $68 \%$ considered themselves to be physics specialists. The teacher survey probed personal information, school facilities, assessment, current practice, pedagogy, aims and obstacles to learning. The student survey probed personal information, school facilities, classroom activities and attitudes to practical work. Both open and

Table 2 The roles and locations of the stakeholders interviewed

\begin{tabular}{lllll}
\hline & Ghana & South Africa & Nigeria & Tanzania \\
Types of stakeholder & & & & \\
\hline Teaching staff & 13 & 19 & 11 & 12 \\
Physics students & 20 & 18 & 16 & 26 \\
Other educational stakeholders & 9 & 8 & 5 & 86 \\
Total & 42 & 45 & & 46 \\
\hline
\end{tabular}


closed questions were included. The surveys were completed in scheduled class time and the response rate for both was $100 \%$. The surveys were piloted in a Nigerian school and the questions were amended marginally to enhance clarity for the respondents.

In this paper, the survey data are presented using descriptive statistics without quantitative inferential analysis. The latter approach is only appropriate when sampling is representative of the larger populations and sample size permits statistically significant conclusions. Our data are derived from several diverse subpopulations with differences in background reflecting the counties and regions visited. There are many relevant variables. The teacher survey includes only 44 respondents. In addition, the survey questions are not identical to those used in previously standardised instruments. Therefore, quantitative comparisons with previous literature would be of dubious validity. The descriptive statistics approach we have used allows large data sets involving multiple variables to be presented in a synoptic way that aids interpretation (Todd, 2007). The responses to the open-ended items in both surveys indicated that the wording of the items was appropriate for the participants concerned.

Summary of Methodology. The importance of each of the data gathering protocols to answering each research question is presented in summary form in Table 3.

\section{Results}

In this section, relevant survey results are summarised before the qualitative data are considered at greater length. Details of both are available via an online repository (Babalola, 2017).

Teachers were asked to rank five teaching aims drafted to reflect previous educational literature. The average order of priority ( 1 is highest) were to as follows:

1. Develop skills in the design of experiments and investigations (rank, 2.2 \pm 1.5 )

2. Encourage skills of working together in a scientific context (rank, 2.8 \pm 1.5 )

3. Make new observations about the natural world (rank, $3.1 \pm 1.5$ )

4. Provide a context for the development of mathematical skills, and (rank, $3.3 \pm 1.5$ )

5. Encourage the development of skills in the design of instruments (rank, $3.45 \pm 1.5$ )

It is likely that the options offered were insufficiently targeted on the teacher's actual aims given the answers to two further questions. Teachers ranked four offered criteria for student success as follows (highest first):

1. Understanding of physics content (rank, $2.1 \pm 0.5$ )

2. Good knowledge of physics content (rank, $2.3 \pm 1.5$ )

3. Application of the knowledge of physics (rank, $2.65 \pm 0.7$ )

4. Skills in practical physics (rank, $3.1 \pm 0.5$ )

When asked about their agreement with eight assertions about effective practical teaching practice, the most strongly supported statements emphasised whole class discussion, getting the right answers and following predefined steps, with only minority support for student-led investigation. Finally, teachers were provided with a list of ten possible barriers 
Table 3 Summary of the overall methodology

\begin{tabular}{llllll}
\hline & Interviews & & & Surveys & \\
\cline { 2 - 3 } \cline { 5 - 6 } Research question & Teachers etc. & Students & & Teachers etc. & Students \\
\hline Educational aims & High & Medium & & High & Medium \\
Comparisons with other countries & Medium & Low & & Medium & Low \\
Barriers and additional aims & High & High & & High & Medium \\
\hline
\end{tabular}

to effective practice and asked to identify the five most important. Time and material resource issues dominated. However, it was also apparent that there were issues of motivation, possibly linked to pay and the level of demands on the teachers.

The students were not asked directly to comment on the aims but their responses do provide some insight into practice. Approximately $90 \%$ said that they enjoyed practical work, and the same percentage asserted that it helped them to understand how physics was carried out beyond school. Eighty-six percent claimed that it helped them to understand concepts. However, nearly 50\% regretted the lack of resources and $73 \%$ disagreed with the statement that they 'do practical work regularly'. Given this last statement, the opinions of the students must be treated with caution.

In analysing the interview responses on the aims of practical physics, five broad themes were chosen that brought together the main strands of stakeholder discussion. These were as follows:

1. Broader physics learning (opinions on understanding and reinforcing the theory)

2. Practical specific learning (skills acquisition and investigation of physics concepts)

3. The exploration opportunities of practical physics

4. Motivation (the interest of the students in physics, linking theory to the real world, relating physics to life activities)

5. Linking of practical physics to economic needs and priorities

The 165 interviewees made 200 separately coded statements on the above five themes (Table 4). Some comments were relevant to more than one theme.

Table 4 Overall themes and number of respondents on aims of practical physics

\begin{tabular}{llllll}
\hline Country & Ghana & S. Africa & Nigeria & Tanzania & Total \\
Number of interviewees & $(42)$ & $(45)$ & $(32)$ & $(46)$ & $(165)$ \\
\hline Broader physics learning & 20 & 17 & 13 & 19 & 69 \\
Practical specific learning & 15 & 19 & 13 & 20 & 67 \\
Exploration and discovery & 4 & 6 & 4 & 1 & 15 \\
Motivation & 7 & 9 & 8 & 3 & 40 \\
Economic needs and priorities & 2 & 1 & 3 & 59 & 200 \\
Total & 48 & 52 & 41 & & 9 \\
\hline
\end{tabular}

The italicized entries indicate the total number of respondents for each countries and themes 
Broader Physics Learning. The largest number of comments related to the perceived impact that practical physics had on broader physics learning, i.e. it enhanced delivery of other parts of the physics curriculum. Participants commented that practical work improved factual knowledge and that it gave students deeper understanding of the subject. Some of the participants also believed that practical physics helps in reinforcing theory. Here are some typical stakeholder remarks.

The aim of the practical physics curriculum is to improve the knowledge of the student ...... Some topics may be difficult to understand, but when you introduce practical, they understand this topic better and they are able to think for themselves. (Teacher, NIG)

Commenting on the potential impact of practical work in improving student understanding of physics, an experienced school principal remarked:

Well, to the best of my knowledge, it is designed to give the student a deeper knowledge of the subject matter in physics. It is not enough for you to know the theory but also the practical aspect of physics.....to confirm what you have taught the students....... is very necessary not only to pass exam alone but to widen the knowledge of students about the subject. (Principal, NIG)

Several educationalists made similar comments, e.g.:

In our college here, we got one idea that before teaching science ........student must know the saying that when I hear, I forget - when I see, I remember - but when I do, I understand...... so, practical helps the students to understand physics concepts. (Educationalist, TAN)

Some stakeholder comments allude to a common belief - that practicals help in reinforcing the theory by making physics more real to the student, i.e. practicals address the veracity of physics by providing a direct confirmation of the theory. A school principal offered this comment.

It is just to reinforce the theory that has been taught to the learners so that they can see the concepts that was taught in class and how it happens. (Principal, SA)

The students commented that practical work improved their knowledge and that it gave them deeper understanding of the subject. Some of the students also believed that practical physics helped in reinforcing the theory that had been taught in class.

I do like to study practical physics because they say practice makes perfect. When I learn the theory and also the practical, I understand more. (Student, TAN)

The students also believed that practical activities in physics helped them to verify the concepts and laws of physics. They argued that, by engaging in practical physics, they are able to see the truth of what is being taught. An enthusiastic student remarked: 
we (students) get to see things practically rather than just hearing about it, for example, I won't believe it if somebody tells me that if you put white light through a triangular prism, it produces seven different colors but when you take the prism and do it yourself, you get to see the different spectrum coming out. (Student, SA)

Other students made similar comments, e.g.:

I like studying practical physics because, when we are engaged in practical activities, it makes us to understand better. Also seeing is believing and whatever we practice will stick to our brain. (Student, NIG)

\section{Practical Specific Learning}

Many participants mentioned some form of skills development in discussing the aims of practical work. They believed that practical physics should enhance instrumental, data analysis and mathematical skills. Other skills such as designing experiments, manipulation of experiments, innovation and creative thinking, observation and report writing were also mentioned. Relevant comments offered by the participants include the following.

Practical helps the students to acquire necessary scientific skills and attitudes so that they will be able to perform better in the modern age of science and technology. (Educationalist, NIG)

It (practical) helps students to develop mental and mathematical skills because if we go through the theory alone, it will not help the student's understanding. (Teacher, TAN)

Skills acquisition is one of the learning outcomes. At the end of the lesson, students should have acquired certain skills in measurement, observation and description. (Educationalist, GH)

Many students included skills development in the aims of practical work in physics. Skills such as designing experiments, handling and manipulation of equipment, innovation and creative thinking, observation and report writing were all mentioned, e.g.:

Well, when we are in practical physics class, first, we learnt how to handle the apparatus because some of us do not know how to handle some of this apparatus and also operating with different apparatus like the galvanometer and ammeter. (Student, TAN)

Some comments referred to personal skills and attitudes, for example:

Practical makes me to be a good observer and am also able to visualize what we've done in the syllabus and am also able to handle apparatus. (Student, NIG)

Practical helps me to develop confidence and give me more experience. (Student, TAN) 
Exploration and Discovery. Some of the stakeholders asserted that practical activities in physics should include the process of discovery and enable personal verification of the facts and laws of physics. A physics curriculum developer remarked:

Practical helps in breaking new ground and in exploration of new ideas. (Educationalist, GH)

Other comments on these issues include the following:

Practical is putting physics to action and it makes things real and not just seeing or writing about it.....practical helps students to investigate most of the laws in physics. (Teacher, NIG)

We don't tell them what the outcome or the objective of the experiment will be .....They find it out themselves. It is a fact finding for them. (Educationalist, SA)

A school principal argued that there is a disconnection between the schools and industry and linked the discovery element of practicals to industrial relevance.

In Africa, relationship between industry and schools is not very strong...... Students should see and touch what they’ve learnt. (Principal, GH)

Similar comments were offered by other participants.

Practical work is very important because learners are able to apply physics concepts most especially in area of industry and they are able to visualize things for themselves. (Teacher, SA)

Motivation. About one third of the participants commented on the effect of practical work on student motivation. They asserted that it can help to arouse and sustain the interest of the students in physics. The following are comments offered by the participants.

Practical physics helps in arousing the interest of the learners and developing their curiosity, and helps them to investigate things around them. (Teacher, SA) Practical work serves as a morale booster for the students to develop interest in physics as a subject. (Teacher, $\mathrm{GH}$ )

It (practical work) is designed to help the students to conceptualize a new approach to problem solving....it will motivate the students and sustain their interest in physics. (Principal, Nigeria)

The direct sensory experience of the laboratory was seen as relevant to motivation. For example,

It is good to teach learners, but they are better off if they see things done in a real sense, this will go a long way in developing their interest in physics. (Head of Department, SA) 
Practical physics is very interesting to the students because of what they can see and touch.....some of the students even prefer to stay in the laboratory throughout the day doing practical than to stay in the theoretical class...... (Teacher, NIG)

Several participants asserted that practical work enhanced motivation by linking what students have learned in physics to what goes on in the natural and industrial environment. By carrying out practical work, they gain insight and are more able to solve life problems.

We .... should be able to relate physics to our environment with the help of practical activities. (Educationalist, TAN)

Practical helps learners to connect to the real world of life. (Head of Department, SA)

The students said that practical work in physics helps them to relate physics to life activities. They enjoy practical physics because it is interesting and fun. They also enjoy the greater freedom they have during practical activities. They believed that their interest is stimulated by direct physical interaction with equipment. The following are comments offered by the students.

In practical physics, we learn how to apply the theoretical knowledge that we gain in class and also find a way of applying physics to our daily life. (Student, TAN) I do like studying practical physics because we get firsthand experience on what we have been taught by the teacher. Also, in the laboratory there is freedom and you do things yourself...I understand practical better than reading it from the textbook. (Student, SA)

Economic Needs and Priorities. Some of the participants relate skills acquisition to the economic needs and priorities of the individual and/or society as a whole. They believed that a student can contribute to the development of a country if he/she acquires the necessary skills. A senior support staff member offered these comments.

Physics education should be hands-on so that, after graduation, students should be able to set up their own industry and use physics to improve their life. (Educationalist, TAN)

Other participants commented similarly.

Yes, I believe that practical is very important because learners are able to build equipment for themselves ... thereby developing the technology of our country........it is essential that skill in using and managing equipment is developed. (Senior Official, TAN)

Practical physics will help students to contribute their quota to national development because any country without science will not move forward. (Teacher, NIG)

Only a few students were able to recognise the role of practical physics in addressing economic needs and priorities, though some saw it as a useful background skill. An 
enthusiastic student appreciated the market value of practical physics equipment and stated as follows:

It makes us to see things in different ways...... I will like to go into the production of equipment and make money from them as I learnt that they are expensive. (Student, SA)

Another student stated the following:

Physics is more useful in our society, it (practical) will help me build my own electric light and also help me in my environment. (Student, TAN)

Several students referred to the future value of physics in daily life. One student linked this explicitly to a career option.

I like physics practical more than any other science practical because physics is very interesting to me due to my future ambition of becoming an Electrical Engineer. (Student, Nigeria)

\section{Discussion}

The declared aims of the stakeholders overlap considerably with the previous literature on the aims of practicals. All can be found in previous lists of aims. This is not surprising as pedagogical beliefs, curriculum content and desired learning outcomes are shared internationally. However, the priorities are less consistent with previous analyses. This section discusses what the data reveals about priorities and about the tacit aims in SSA. The section is structured by the themes adopted in setting out the results.

Broader Physics Learning. Many stakeholders asserted that practical work provides a broader curriculum service in consolidating knowledge and understanding, though many responses did not define how the pedagogy supported that role. This ambiguity may be because the schedule and delivery of practical experiences is limited and weakly structured in many schools. The stakeholders' assertions were in line with Hodson (1990) who argued that practical work helps to 'enhance the learning of scientific knowledge'. This view has been supported by other authors (Bennett, 2003; Parkinson, 2004; Shulman \& Tamir, 1973). Wellington (1998) grouped the reasons for doing practical work under three broad headings: cognitive, affective and skills. The cognitive aims were to improve pupil understanding and to help to confirm theory.

However, content-understanding aims are not explicit in many published lists of the aims of practical physics. For example, the SCORE report only includes one content related aim at sixth priority out of nine (SCORE, 2008). Are such differences in view because knowledge and understanding aims are tacit and those constructing lists are looking for aims that are specific to practical experiences? It may be because broader 
curriculum aims are not the priority for those able to devote considerable resources to delivering the curriculum. Perhaps, teachers who cannot assume that the learning of content/understanding is adequately covered, or who are hard stretched, see practical physics as an additional opportunity to cover the elements they consider most essential for qualification success.

Practical Specific Learning. The stakeholders' responses identified several practical physics aims, notably enhancing instrumental, data analysis and mathematical skills. Other skills were also mentioned. These assertions are in line with several authors (Hofstein \& Lunetta, 2003; Muhasia, Muliro, Abacha \& Biyoyo, 2012; SCORE, 2008; Watson, 2000). These claims do not appear to be contentious. Wellington (1998) also argued that practical work develops not only manipulative or manual dexterity skills, but also promotes higher level transferable skills such as observation, measurement, prediction and inference. However, Wellington offered a cautionary comment on his claims by asserting that 'the evidence for the transferability of skills is limited'.

Although the stakeholders were clear about the importance of skills-related aims, there was an emphasis on low order skills, e.g. gaining familiarity with and using traditional and essentially obsolete equipment, drawing graphs, carrying out basic statistical analyses. There was little sense that the skills were being learnt because of a contemporary purpose that extended beyond the passing of exams. In spite of such limitations, the students appear to enjoy the practicals.

Exploration and Discovery. Only 15 stakeholder responses related to exploration and discovery. This low priority was consistent with the limited support for student-led investigation in the survey but contrasts with the high priority suggested in other reports (SCORE, 2008). The difference may reflect pedagogical norms. Many well-resourced educational systems have promoted student-led and discovery-based learning. The teacher's role has shifted to some extent from the provider of knowledge to the facilitator of knowledge and skills acquisition.

In SSA, large class sizes and assumptions of teacher authority may militate against the introduction of open-ended learning experiences. Nevertheless, some stakeholders have suggested that practical work should be thought of as 'fact finding-missions' and that students should be able to discover as well as being told. These roles appear in the lists developed in previous studies (Beatty \& Woolnough, 1982; Kerr, 1963; Parkinson, 2004; Swain, Monk \& Johnson, 1999). Although these views are offered by science/ physics teachers in SSA, there is effectively no evidence that they are translated into practice - they can only be regarded as aspirational.

Motivation. Many stakeholders have asserted that the sensory nature of practical activities can help to arouse and sustain the interest of the students in physics. The tangibility suggested relevance. Many of those interviewed asserted that practical work helped learners to relate what they have learnt in physics to what goes on in the natural and industrial environment (Table 4). By carrying out practical work, students gain insight and are more able to solve life problems.

Similar findings were reported by Collins (2011), who argued that practical work creates motivation and interest for learning physics as it allows tacit knowledge of scientific phenomena to be gained. Millar (1998) has also argued that practical work 
should be viewed as an important means of allowing physics learners to reconcile and link the physical world with its physics description. Several other authors have argued similarly (Bennett, 2003; Hodson, 1990; Kerr, 1963; Parkinson, 2004; Watson, 2000).

Overall, the evidence for the relevance of motivation in SSA practice is not convincing. The comments made by stakeholders tend to be very general and to be lacking in the vivid anecdotes that would suggest real impact. Students who have little exposure to instrumentation and measurement cannot be reporting their direct experience and may just be anticipating that novelty would be motivating. There is little evidence that students have grounded expectations that practical work will have employment relevance which has high priority for SSA students.

Economic Needs and Priorities. Some stakeholders related skills acquisition to the economic needs and priorities of the individual and society as a whole. They asserted that students can contribute to the development of a country if they acquire the necessary skills. This was supported by some students who were able to recognise the role of practical physics in addressing economic needs and priorities and saw it as a useful background skill. The economic imperative is included in the aims listed in the physics curriculum documents of the countries involved in this study. However, once again, such aims have limited credibility. There are few employment opportunities that are specifically reliant on a physics qualification and physics is not an obvious area for small-scale private enterprise. It is telling that some stakeholders remarked that the obvious path for those specialising in physics would be to become educators - in most SSA countries, teaching is not a highly paid profession.

\section{Conclusions}

Although previous literature has suggested diverse aims for practical physics education, priority has been generally given to the acquisition of both professional and transferable skills. It is clear that aims drawn from the literature do not describe either the views of stakeholders or practice in SSA where the most important learning and teaching role of practical work was considered to be understanding of physics content and reinforcement of theory. The following list expresses the aspirations that are revealed in this study (Research Question 1).

1. Supporting the understanding of physics concepts

2. Reinforcing the theory learnt in physics

3. Acquiring professional skills

4. Exploring and illustrating physics laws

5. Motivating students

6. Nurturing the personal development and life skills of students

7. Contributing to national economic development

These cover similar ground to previous analyses but are different in emphasis (Research Question 2). It is quite clear that the practice revealed in this study could not deliver these aims without major reform. The exam systems are based overwhelmingly on factual recall which militates against the higher order learning included in the national 
curriculum aims. In turn, the exam priorities influence resource allocation, teaching priorities and student attitudes.

Little attention is given to practical physics. The difficulty of managing large classes places obstacles in the way of effective and imaginative practical work. So, the working aims of those designing the learning, primarily the teachers, are a balance between aspiration and achievability and the pragmatic aims of overcoming day to day obstacles dominate (Research Question 3).

These issues must be considered in planning any intervention aimed at improving practical physics teaching in SSA. Initiatives that target individual problems such as resource shortages or teacher skills are unlikely to have limited impact without accompanying systemic change.

This study has generated sufficient data to expose the issues involved in the teaching of practical physics in SSA, but has several limitations. The coverage is not comprehensive in terms of the number of countries studied and the inclusion of a representative number of rural schools. The instruments used give insufficient attention to major drivers of behaviour such as assessment policy, employment opportunities and do not explore the relevance of traditional attitudes to science and hierarchy. Although the instruments included open-ended questions, they direct attention towards issues that have been raised previously and, in so doing, may neglect novel or local opinion. This limitation has been raised previously (Justi \& Gilbert, 2005). It is arguable too that surveys and interviews are limited in their ability to extract information about genuine attitudes. It would be helpful to develop the research protocols further to target more precisely the issues raised and to facilitate inter country comparisons.

Acknowledgements Special thanks to all the stakeholders who participated in this study.

Funding Information We are highly indebted to the Institute of Physics and the Open University — both in the UK-for providing the funding for this research work.

\section{Compliance with Ethical Standards}

Ethical approval for the research was sought and obtained from the Human Research Ethics Committee of the UK Open University and from the Ministry of Education in each country. In addition, written informed consent was sought from the head teachers of each school and the science/physics teachers who were to be participants in the study. All participants were reassured that there was no personal risk associated with participation, and that they would be free to withdraw from the study at any time without penalty. Their views would be anonymised.

Open Access This article is distributed under the terms of the Creative Commons Attribution 4.0 International License (http://creativecommons.org/licenses/by/4.0/), which permits unrestricted use, distribution, and reproduction in any medium, provided you give appropriate credit to the original author(s) and the source, provide a link to the Creative Commons license, and indicate if changes were made.

\section{References}

Abrahams, I. \& Sağlam, M. (2010). A study of teachers' views towards practical work in secondary schools in England and Wales. International Journal of Science Education, Taylor Francis (Routledge), 32(06), $753-768$. 
Babalola, F. E. (2017). Advancing practical physics in Africa's schools (Doctoral dissertation). The Open University, Milton Keynes, England.

Baird, J. R. (1990). Metacognition, purposeful enquiry and conceptual change. In E. Hegarty-Hazel (Ed.), The student laboratory \& the science curriculum (pp. 183-200). London, England: Routledge.

Beatty, J. W. \& Woolnough, B. E. (1982). Why do practical work in 11-13 science? The School Science Review, 63(225), 768-770.

Bennett, J. (2003). Teaching and learning science: A guide to recent research and its applications. London, England: Continuum.

Bentley, D. \& Watts, M. (1991). Constructivism in the curriculum. Can we close the gap between the strong theoretical version and the weak version of theory in practice? The Curriculum Journal, 2(2), 171-182.

Bing, W. \& Hao, L. (2018). An experienced chemistry teacher's practical knowledge of teaching with practical work: The PCK perspective. Chemical Education Research and Practice, 19, 452-462.

Bogdan, R. C. \& Biklen, S. K. (2007). Qualitative research for education: An introduction to theory and methods (5th ed.). Boston, MA: Pearson Education.

Collins, S. (2011). What do students think about science? In R. Toplis (Ed.), How science works: Exploring effective pedagogy and practice (pp. 14-30). Oxon, England: Routledge.

Driver, R. \& Oldham, V. (1986). A constructivist approach to curriculum development. Studies in Science Education, 13, 105-122.

Fessehatsion, H. W. (2003). An investigation of the current challenges in the implementation of grade II chemistry practical work in three selected secondary schools in Eritrea (M.Ed. Published Minithesis). University of the Western Cape, South Africa.

Ghebremariam, G. H. (2000). An evaluation of grade 10 physics practical work in five selected secondary schools in Eritrea (M.Ed. thesis). University of the Western Cape, South Africa.

Hodson, D. (1990). A critical look at practical work in school science. School Science Review, 71(256), 33-40.

Hodson, D. (1998). Teaching and learning science, towards a personalised approach. Buckingham, England: Open University Press.

Hofstein, A. \& Lunetta, V. N. (2003). The laboratory in science education: Foundations for the twenty-first century. Willey Periodicals, Inc., 88, 28-54.

House of Lords (2006). Science Teaching in Schools. Science and Technology Committee, 10th Report of Session 2005-06, pp8.

Justi, R. \& Gilbert, J. K. (2005). Investigating teachers' ideas about models and modelling-some issues of authenticity. In K. Boersma, M. Goedhart, O. D. Jong \& H. Eijelholf (Eds.), Research and the quality of science education (pp. 325-336). Dordrecht, The Netherlands: Springer.

Kang, N. H. \& Wallace, C. S. (2005). Secondary science teachers' use of laboratory activities: Linking epistemological beliefs, goals, and practices. Science Education, 89(1), 140-165.

Kerr, J. F. (1963). Practical work in school science: An account of an inquiry into the nature and purpose of practical work in school science teaching in England and Wales. Leicester, England: University Press.

Kirschner, P. (1992). Epistemology, practical work and academic skills in science education. Science Education, 1, 273-299.

Lazarowitz, R. \& Tamir, P. (1994). Research on using laboratory instruction in science. In D. L. Gabel (Ed.), Handbook of research on science teaching \& learning (pp 94-130). New York, NY: Macmillan.

Lunetta, V. N., Hofstein, A. \& Clough, M. P. (2007). Teaching and learning in the school science laboratory. An analysis of research, theory, and practice. In S. K. Abell \& N. G. Lederman (Eds.), Handbook of research on science education (pp. 393-431). Mahwah, NJ: Lawrence Erlbaum Associates.

Mayer, R. E. (2004). Should there be a three-strikes rule against pure discovery learning? The case for guided methods of instruction. American Psychologist, 59(1), 14-19.

Millar, R. (1998). Rhetoric and reality: What practical work in science education is really for? In J. Wellington (Ed.), Practical work in school science: Which way now? (pp. 16-31). London, England: Routledge.

Millar, R. (2010). Practical work. In J. Dillion \& J. Osborne (Eds.), Good practice in science teaching: What research has to say (2nd ed., pp. 108-134). London, England: McGraw-Hill.

Muhasia, A. M., Muliro, M., Abacha, O. A. \& Biyoyo, M. E. (2012). Effect of practical work in physics on girls' performance, attitude change and skills acquisition in the form two-form three secondary schools' transition in Kenya. International Journal of Humanities and Social Science, 2(23), 151-166.

National Council of Educational Research and Training [NCERT] (2006). Pedagogy of science: Physical science, textbook for B.Ed. New Delhi, India: Author.

Parkinson, J. (2004). Improving secondary science teaching. London, England: Routledge Falmer.

Said Z., Friesen H. \& Al-Azzah H. (2014). The importance of practical activities in school science: Perspectives of independent school teachers in Qatari schools. In L. Gómez Chova, A. López Martínez 
\& I. Candel Torres (Eds.), EDULEARN14 Proceedings: 6th International Conference on Education and New Learning Technologies (pp. 4847-4856). Barcelona, Spain: IATED Academy.

Science Community Representing Education [SCORE] (2008). Practical work in science: A report and proposal for a strategic framework. Retrieved in July, 2017 from http://www.score-education. org/media/3668/report.pdf.

Shulman, L. S. \& Tamir, P. (1973). Research on teaching in the natural science. In R. M. Travers (Ed.), Second handbook of research on teaching: A project of the America educational research association (pp. 10181148). Chicago, IL: Rand McNally and Company.

Sturman, L., Ruddock, G., Burge, B., Styles, B., Lin, Y. \& Vappula, H. (2008). England's achievement in TIMSS 2007 national report for England. Slough, England: NFER.

Swain, J. R. L., Monk, M. \& Johnson, S. (1999). A comparative study of attitudes to the aims of practical work in science education in Egypt, Korea and the UK. International Journal of Science Education, 21(12), 1311-1323.

Thompson, J. J. (1975). Practical work in sixth form science. Oxford, England: Science Centre.

Tobin, K. G. (1990). Research on science laboratory activities. In pursuit of better questions and answers to improve learning. School Science and Mathematics, 90, 403-418.

Todd, N. G. (2007). Descriptive statistics. In W. T. Ambrosius (Ed.), Topics in biostatistics. Methods in molecular biology ${ }^{\mathrm{TM}}$ (Vol. 404, pp. 33-52). New York, NY: Springer.

Ünal, C. \& Özdemir, O. F. (2013). A physics laboratory course designed using problem-based learning for prospective physics teachers. European Journal of Science and Mathematics Education., 1(1), 29-33.

Watson, J. R. (2000). The role of practical work. In M. Monk \& J. Osborne (Eds.), Good practice in science teaching. What research has to say? (pp 57-71). Buckingham, England: Open University Press.

Woodley, E. (2009). Practical work in school science. Why is it important? School Science Review, 91(335), 49-51.

Wellington, J. (Ed.) (1998). Practical work in school science: Which way now? London, England: Routledge. 